\title{
A CEPAL AINDA É UMA ESCOLA DO PENSAMENTO?*
}

\author{
Niemeyer Almeida Filho ${ }^{\star *}$ \\ Vanessa Petrelli Corrêa ${ }^{\star * *}$
}

\begin{abstract}
RESUMO O artigo discute se a CEPAL ainda se constitui como uma Escola do Pensamento, status que lhe foi conferido por diversos livros especializados na discussão das Teorias do Desenvolvimento. A tese sustentada no artigo é a de que esta condição de Escola do Pensamento foi muito específica de uma situação de funcionamento da agência nos seus primeiros anos de existência, no contexto de um debate sobre que políticas de desenvolvimento deveriam ser implementadas para que países subdesenvolvidos pudessem almejar o desenvolvimento. $\mathrm{O}$ artigo procura estabelecer uma diferenciação entre esta condição dos primeiros anos e a atual, mostrando que agora a agência tem uma atuação compatível com a sua natureza de órgão multilateral pertencente ao esquema institucional das Nações Unidas.
\end{abstract}

PALAVRAS-ChAVE: CEPAL; políticas de desenvolvimento; teorias do desenvolvimento

\section{IS ECLAC STILL A SCHOOL OF THOUGHT?}

ABSTRACT The article discusses if ECLAC still constitutes a School of Thought, status conferred on it by several specialized books in the discussion of theories of development. The thesis advanced in the article is that this condition of the School of Thought was a very specific situation of the agency in its early years, in the context of a debate on if development policies should be implemented so that developing countries could aspire to development. This paper attempts to differentiate between this condition of early years and the current, showing that now the agency has a role compatible with their nature as multilateral body belonging to the institutional framework of the United Nations.

KEY-WORDS: ECLAC; development policies, development theories

JEL CLASSIFICATION: B20

\footnotetext{
*Artigo enviado em 10 de julho de 2010 e aprovado em 6 de maio de 2011.

**Professor Associado do Instituto de Economia da Universidade Federal de Uberlândia. Doutor em Economia pelo IE-UNICAMP. Contato: nafilho@ufu.br.

${ }^{* * *}$ Professora Associada do Instituto de Economia da Universidade Federal de Uberlândia. Doutora em Economia pelo IE-UNICAMP. Contato: vanplli@ufu.br.
} 


\section{INTRODUÇÃO}

A CEPAL é uma das cinco Comissões Econômicas criadas em 1948 pelo Conselho Econômico e Social das Nações Unidas com o objetivo de contribuir para o desenvolvimento econômico da América Latina, mediante a coordenação de ações econômicas destinadas a promover esse desenvolvimento, além de reforçar as relações dos países da região entre si e com os demais países do mundo. Essa missão inscreve-se no ideário mais amplo que orientou a criação das Nações Unidas, responsável pela consolidação do espaço supranacional em um espaço multilateral de governança política e, sobretudo, econômica'. Portanto, a missão inscreve-se naquilo que poderia ser identificado como "os valores próprios da civilização ocidental"2.

Um observador recente da CEPAL poderia dizer, sem muita dificuldade, que essa missão original, que motivou a criação da agência, traduz-se em diretrizes, práticas e ações bastante identificadas com o ideário das Nações Unidas. Portanto, sugere-se que para este observador seria natural afirmar que a CEPAL enquadra-se no papel para o qual ela foi criada.

Contudo, a CEPAL foi, durante os anos 1950, e até os anos 1970, uma Escola do Pensamento, isto é, foi responsável por uma interpretação do desenvolvimento econômico da América Latina que confrontava alguns aspectos fundamentais da visão dominante do desenvolvimento, norteadora das ações de recuperação das economias no imediato pós-guerra, sobretudo a partir da implementação do Plano Marshall em 1947.

Nesse período, a visão dominante era de que as diferenças de desenvolvimento, que eram ali claramente percebidas, eram resultado de condições históricas particulares de cada país, que tendiam a ser superadas pela ultrapassagem das fases necessárias do desenvolvimento econômico, caminho já desenhado e trilhado pelos EUA. Assim, bastaria que as economias nacionais expandissem as suas atividades produtivas tradicionais e incrementassem o comércio internacional para que o desenvolvimento econômico fosse alcançado.

Diferentemente, a CEPAL sustentava que a divisão internacional do trabalho que se apresentava no pós-guerra não permitiria que os países mais pobres (subdesenvolvidos) alcançassem o nível do desenvolvimento dos EUA, por exemplo. A manutenção e

\footnotetext{
${ }^{1}$ Esta é a tese central do livro de Murphy (1994), que sustenta que a governança supranacional foi sempre funcional ao desenvolvimento capitalista, particularmente no período do pós-segunda guerra mundial.

${ }^{2} \mathrm{O}$ sentido que damos ao termo "civilização ocidental" é algo impreciso, tendo como referência os valores morais e os princípios políticos que foram sendo forjados pelo desenvolvimento capitalista ao longo da idade moderna. Nesta civilização, a ação dos Estados é essencial para a estabilidade social.
} 
a reprodução da especialização produtiva das economias latino-americanas tenderiam, ao contrário, a aumentar as disparidades de níveis de desenvolvimento, pela deterioração progressiva e tendencial dos termos de troca.

A formulação mais ampla do argumento - que aqui não cabe reproduzir, por não ser essencial aos nossos propósitos - ficou conhecida na literatura como a interpretação cepalina do desenvolvimento ${ }^{3}$. Além disso, a formulação sustentou, por um período mínimo de vinte anos, as políticas econômicas dos países da América Latina, que se voltaram para um processo de industrialização liderado e financiado significativamente pelos recursos dos Estados Nacionais.

Nosso objetivo neste artigo é realçar que o fato de a CEPAL ter sido identificada como uma Escola do Pensamento deve-se a uma circunstância histórica particular. Isso só foi possível pelas condições iniciais de operação daquela agência, seja pela ótica interna de uma instituição em processo de consolidação, em uma fase em que a própria ONU se firmava no espaço internacional, seja pela natureza mesma do ideário que orientava as ações estratégicas dos EUA e dos seus aliados europeus. Há, ainda, um contexto econômico favorável, em que as ações industrializantes encaixavam-se às estratégias de internacionalização produtiva das empresas multinacionais.

Registre-se que esta nossa perspectiva é distinta da discussão que se apresenta nos espaços acadêmicos a respeito do papel da CEPAL. Há uma crítica bastante consolidada que vê as ações atuais da agência como expressão de uma mudança significativa de orientação política em relação ao seu papel histórico. Entende-se que a natureza das recomendações da CEPAL quanto a políticas de desenvolvimento, pelo menos desde os anos 1990, vem se afastando significativamente daquela natureza dos anos 1950. Nesse sentido, haveria um "aparelhamento" da instituição pelo pensamento dominante, que vê o desenvolvimento como um processo que ocorre essencialmente pela operação dos mercados.

Nossa tese é que o funcionamento atual é muito mais identificado com o de organismos multilaterais do que aquele dos anos 1950. Assim, invertemos a lógica do raciocínio para colocar em discussão a tese de que a mudança recente de orientação teórica e prática (as recomendações de políticas) é um encontro genuíno com a sua natureza de instituição das Nações Unidas, ficando o funcionamento dos anos 1950 e 1960 como um interregno extraordinário.

Para discutir esta questão, o artigo está organizado em três seções além desta introdução. A primeira mostra a mudança de perspectiva da CEPAL na passagem

\footnotetext{
${ }^{3}$ ver Hunt (1989), Kay (1989) e Hette (1990). Esses são três dos trabalhos que fazem a resenha das teorias do desenvolvimento. Neles é possível aferir a importância que se confere à CEPAL no contexto do debate sobre o desenvolvimento que ocorre nos anos 1950 e 1960.
} 
dos anos 1980 aos anos 1990. A segunda mostra como essa mudança foi determinada por uma forma de operação própria dos organismos multilaterais, que se consolida dos anos 1970 em diante, quando há uma mudança de ênfase na operação das relações internacionais da economia para a política e do desenvolvimento para os direitos humanos fundamentais. Finalmente, na terceira seção, apresentamos uma síntese dos argumentos.

\section{A NATUREZA DAS RECOMENDAÇÕES DA CEPAL DESDE OS ANOS 1990}

Embora nossa intenção seja mostrar a excepcionalidade do funcionamento da CEPAL nos anos 1950 e 1960, quando, não obstante a sua condição de agência multilateral das Nações Unidas, o órgão apresentou autonomia de operação e de interpretação da realidade, é indispensável caracterizar uma mudança de perspectiva, que só se viabiliza pela comparação de diagnósticos e recomendações de políticas de desenvolvimento. Vejamos.

Em março de 1990, a CEPAL deu publicidade a um estudo intitulado “Transformação Produtiva com Equidade: a Tarefa Prioritária do Desenvolvimento da América Latina e do Caribe nos Anos Noventa", coordenado por Fernando Fajnzylber. Trata-se de um documento singular para a Agência, pelo seu foco parcial em questões macroeconômicas, embora em grande parte genérico nas suas proposições de políticas.

O seu ponto de partida é o diagnóstico de retrocesso regional da grande maioria das economias nacionais latino-americanas e do Caribe, sobretudo se o desempenho for comparado com o período do imediato pós-guerra até a primeira crise do petróleo.

A base empírica utilizada não deixa margem a dúvidas: o produto real per capita regional ao final de 1989 retrocedeu ao registrado 13 anos antes, e até mais do que isso, no caso de algumas economias. Portanto, no momento de realização do estudo, os países da região estavam iniciando a década de 1990 com “o peso da inércia recessiva dos anos 1980, com o passivo representado pelas suas dívidas externas, e com a presença de uma inadequação fundamental entre as estruturas da demanda internacional e a composição das exportações latino-americanas e caribenhas." (Síntese CEPAL, 1990:889).

Diante deste quadro, apontavam-se como desafios dos anos 1990 o encontro dos caminhos perdidos do desenvolvimento (crescimento sustentável) e o fortalecimento da democracia. Esses desafios traduziam-se no ajustamento das economias

\footnotetext{
${ }^{4}$ Utilizaremos tanto o texto original completo (CEPAL, 1990), publicado em espanhol, quanto a síntese publicada em português na coletânea organizada por Bielschowski (2000).
} 
às condições daquela conjuntura, com estabilização; com incorporação ao processo de mudança tecnológica mundial, altamente intensificado; com modernização dos setores públicos; com aumento de poupança; com melhoria da distribuição de renda; e com a implantação de padrões mais austeros de consumo, de modo a criar as condições ao desenvolvimento sustentável em termos ambientais.

A estratégia sugerida era de transformação produtiva com equidade, a ser alcançada por maior competitividade internacional. Esta deveria apoiar-se intensamente na incorporação deliberada e sistemática do progresso técnico ao processo produtivo (com os conseqüentes aumentos de produtividade) e menos na depreciação dos salários reais. Assinalava-se que esta forma havia sido insuficientemente utilizada pela região no passado.

A estratégia exigiria uma combinação do manejo macroeconômico com políticas setoriais, bem como a integração das políticas de curto e longo prazos. Além disso, exigiria mudanças institucionais com orientações de longo prazo, nas quais se pudesse consolidar uma nova forma de interação entre os agentes públicos e privados, como uma via inescapável para atingir a equidade e a harmonia social. Dessa forma, a interação era vista como parte de um novo relacionamento global entre o Estado e a sociedade civil.

Complementando este último aspecto, um dos destaques inovadores do documento é a importância conferida ao âmbito macroeconômico e às políticas que o configuram. Entendia-se que os desequilíbrios de curto prazo haviam que ser superados para que as ações de médio e longo prazo fossem empreendidas. A este respeito, sublinha-se, com ênfase, a importância de um contexto que confira coerência aos diferentes componentes da política econômica de curto prazo e de um grau aceitável de estabilidade de sua aplicação.

Los desequilibrios macroeconómicos de los años ochenta alcanzaron magnitudes sin precedentes. Tales desajustes se dieron, además, en forma simultánea en los planos externo, fiscal y productivo, manifestándose en forma de estrechez de divisas, altas tasas inflacionarias, baja inversión y su-utilización de la capacidad instalada. Por otra parte, como quedó señalado en el capítulo precedente, tanto los desbordes inflacionarios como el intento de restaurar los equilibrios significaron ingerentes costos sociales, traduciéndose, de hecho, en mayores desigualdades.

Una lección central que emerge de la experiencia de los años ochenta es que, para crecer en forma sólida y sostenida, es indispensable mantener los equilibrios macroeconómicos. (CEPAL, 1990, p. 48)

Em outras palavras, adquire aí importância extraordinária (sic) a política fiscal no conjunto dos instrumentos de que os governos disporiam para fazer frente a objetivos às vezes opostos, como a estabilização, o crescimento e a maior justiça distributiva. 
O financiamento da transformação produtiva, na sua vertente interna, exigiria um ajuste da política tributária, a fim de aumentar a poupança pública passível de ser destinada ao investimento. Seria preciso, ainda, fazer um esforço para melhorar a destinação dos gastos, porém, de maneira concomitante a reformas tributárias, que garantissem ampla cobertura dos ramos industriais, preferencialmente a taxas uniformes.

$\mathrm{Na}$ sua vertente externa, o atendimento da transformação produtiva exigiria uma maior abertura da economia, utilizando-se os instrumentos das políticas comerciais e cambiais, como meio de induzir aumentos de produtividade e estímulos à incorporação do progresso técnico. A expectativa era de que essas modificações ampliassem a entrada de capitais externos, ampliando a taxa de investimentos da economia.

No contexto em que veio a público, o documento "Transformación Productiva" emblematizou uma importante mudança de rumos na concepção da CEPAL, uma vez que se trata de um documento oficial, que contava, portanto, com a concordância dos países membros 5 . O momento de divulgação dessas idéias coincide, em conjuntura, com a realização da conferência organizada pelo Instituto de Economia Internacional em 1989, em Washington, evento no qual um trabalho apresentado por John Williamson - Senior Fellow do mesmo instituto - acabou por cunhar a expressão "Consenso de Washington", para expressar um conjunto de pontos de política econômica que vinham sendo adotados pelos países da América Latina e Caribe ${ }^{6}$. Neste sentido, o Consenso era ao mesmo tempo uma síntese do que estava em curso, bem como uma recomendação de "boa prática" de política.

É possível registrar pontos em comum entre as recomendações de política econômica elaboradas pela CEPAL e a síntese do "Consenso de Washington". Dentre esses pontos, os mais relevantes, e que ganharam peso na estratégia da CEPAL, são a disciplina e reforma fiscais, a competitividade real pela via do mercado, com abertura de mercado e ampliação de exportações, e a circunscrição do Estado ao papel regulador7.

Esta mudança de rumos é reconhecida por pesquisadores das idéias da CEPAL. Ricardo Bielschowsky (2000), por exemplo, em seu artigo resenha de apresentação à coletânea que marcou os cinqüenta anos de pensamento da CEPAL, refere-se a este aspecto da seguinte forma:

\footnotetext{
${ }^{5}$ É preciso registrar que esta concordância tem de ser qualificada, pois a importância política dos membros não é homogênea. Não há registros das votações nas sessões de aprovação dos documentos. Contudo, não há tampouco registros de controvérsias.

${ }^{6}$ Um detalhamento das aproximações entre as proposições do "consenso" e as proposições da CEPAL podem ser encontrados em Almeida Filho (2003), Vitagliano (2009) e Corazza (2006). Este último artigo trata ainda do conceito de "regionalismo aberto" para caracterizar a nova perspectiva da CEPAL desde os anos 1990. Para uma visão "de dentro", veja CEPAL (2004; 2008).

${ }^{7}$ ver Almeida Filho (2003).
} 
A implantação das reformas \{propostas pelo ideário neoliberal\} suscita entusiasmos e apreensões, expressos em acalorado debate ideológico, frequentemente polarizado. A CEPAL dos anos 1990 logrou posicionar-se com grande habilidade entre os dois extremos. Não se colocou contra a maré das reformas, ao contrário, em tese tendeu a apoiá-las, mas subordinou sua apreciação do processo ao critério da existência de uma "estratégia" reformista que pudesse maximizar seus benefícios e minimizar suas deficiências a médio e longo prazo.

$\mathrm{O}$ "neo-estruturalismo" cepalino recupera a agenda de análises e de políticas de desenvolvimento, adaptando-a aos novos tempos de abertura e globalização. Avalia que no passado houve, em muitos países, demasiada complacência com a inflação e que os novos tempos exigem alterações na forma de intervenção do Estado na economia, buscando-se ampliar sua eficiência. São tempos de "compromisso" entre a admissão da conveniência de que se ampliem as funções do mercado e a defesa da prática de intervenção governamental mais seletiva. O "compromisso" permite que a análise e as proposições de políticas voltem aos temas caros à CEPAL, ou seja, o progresso técnico e distribuição de renda, abrindo diálogo à direita e à esquerda do espectro retórico e ideológico internacional. (p. 63-64)

Esta passagem é esclarecedora. É possível observar-se uma notável adesão interna dos quadros técnicos da CEPAL, e, não por acaso, das políticas econômicas regionais, a essa "estratégia". Isso pode ser percebido nos estudos que se seguiram ao “Transformación Productiva", que, na maior parte dos casos, parecem detalhar aspectos ali apontados, ou, quando muito, registrar dificuldades de efetivação da estratégia ${ }^{8}$. De uma forma geral, outras publicações da CEPAL como a Série Monográfica, os Cadernos Estatísticos e os Estudos e Informes não tiveram a repercussão ou a abrangência do "Transformación Productiva”.

Uma exceção em termos de amplitude é o documento "Equidad, desarrollo y ciudadanía”, publicado em 2000. Trata-se, inclusive, de um documento mais extenso e detalhado do que o "Transformación Productiva", apontando, talvez, para uma disposição de divulgar a posição oficial da instituição ao final de cada década, o que permite uma revisão das teses fundamentais.

\footnotetext{
${ }^{8}$ A este respeito, podemos citar o documento "Equidad, Desarollo y Ciudadanía", publicado em 2000. À página 14, no item Resumo Executivo, há um balanço da década de noventa, a título de uma consideração dos "legados e desafios" para o novo século. Fica clara a manutenção da perspectiva do "Transformação Produtiva”. Considera-se que houve progressos importantes na correção dos desequilíbrios macroeconômicos, porém, houve efeitos negativos sobre o crescimento econômico e aumento da produtividade. Rodrigues (2009: 564) dá destaque ao documento de 1998, pois nele se relaciona o tema fiscal ao do Estado.
} 
Esse novo documento é organizado em três partes, relativas:

i) ao diagnóstico dos resultados socioeconômicos dos países da região ao longo dos anos 1990;

ii) à defesa da incorporação aos objetivos nacionais de uma política social universal, solidária e eficiente;

iii) a uma proposta de ajuste da estratégia de desenvolvimento que vinha sendo adotada pelos países da região. O que se observa, contudo, é que não há uma modificação em relação ao "Transformación Productiva” que possa marcar uma nova inflexão de concepção e estratégia.

$\mathrm{O}$ "Transformación Productiva” foi organizado por Fernando Fajnzylber", como já o dissemos, porém muito mais do que este trabalho, a formulação das idéias principais têm origem em dois estudos seus anteriores: La Industrialización Trunca (1983); e Industrialización en América Latina: de la 'Caja Negra’ al 'Casillero Vacio’ (1989). Este último trabalho evidencia uma dupla condição dos países da América Latina de baixo crescimento da renda per capita e grande concentração da renda. O "classificador vazio" é definido a partir de um quadro em que se cruzam um "indicador de equidade" com um "indicador de crescimento", de modo a configurar quatro "classificadores":

a) crescimento baixo com concentração de renda;

b) crescimento alto com concentração de renda;

c) crescimento baixo com renda bem distribuída;

d) crescimento alto com renda bem distribuída. Este último consiste no "Classificador Vazio", uma vez que nele não se encontram quaisquer dos países da região. A partir daí, o alvo sugerido do desenvolvimento é o de preencher este espaço vazio, colocando nele todos os países da região.

Entendemos que esta caracterização em si, bem como a ênfase dada nos dois trabalhos de Fajnzylber à importância contemporânea do progresso técnico, enfim, os temas tratados, estão inteiramente enquadrados na tradição da Escola Cepalina. Todavia, a mudança está dada no diagnóstico da situação dos países da região e,

\footnotetext{
${ }^{9}$ Esta é uma interpretação, baseada em informações constantes do documento, e também baseada na publicação anterior de duas obras de Fajnzylber que são referências indispensáveis ao documento "Transformación Productiva", e que estão citadas no texto que se segue. Porém, é preciso registrar que os documentos oficiais são normalmente organizados pelos secretários executivos. Naquele período histórico, o secretário executivo era Gert Rosenthal.
} 
sobretudo, na estratégia pensada para a superação. Esta consiste virtualmente em uma "estratégia microeconômica", pois ao Estado caberia apenas criar condições favoráveis para que os "fatores de produtividade", todos eles internos às empresas, pudessem se concretizar. Não se leva privilegiadamente em consideração a divisão internacional do trabalho, que é um elemento característico do nível de abstração e agregação das economias nacionais.

O ponto a firmar é que a perspectiva inaugurada pelo "Transformación Productiva" apresenta um afastamento significativo daquela perspectiva histórica que fez com que a CEPAL fosse identificada como uma Escola do Pensamento, destacando as características estruturais dos países subdesenvolvidos. As justificativas, sintetizadas na citação que fizemos de Bielshowsky (2000), parecem-nos pertinentes e legítimas para uma agência que procura traduzir as necessidades e posições dos governos dos seus Estados Membros ${ }^{10}$.

Vejamos agora como esta inflexão de natureza de recomendações se insere no contexto supranacional dos anos 1990 em diante.

\section{A NATUREZA DOS ORGANISMOS MULTILATERAIS: INCOMPATIBILIDADE COM UMA "ESCOLA DO PENSAMENTO"}

Constatada a mudança de concepção, resta-nos levantar os seus determinantes. A literatura crítica à condução recente da CEPAL, como vimos, centra os seus argumentos em uma mudança de perspectiva da Agência em sintonia, ou em aproximação, ao que foi fortemente (e ainda é) a ideologia neoliberal nos anos $1990^{11}$. As razões são ideológicas e de exercício de hegemonia interna à agência, a partir de condições históricas próprias ao espaço supranacional mesmo ${ }^{12}$. Aqui não há discordância. Não obstante, a questão que para nós se apresenta está em saber se a perspectiva atual da CEPAL poderia ser diferente, mantendo, por exemplo, uma linha de pensamento e condução autônoma, e abertamente crítica ao desenvolvimento global.Nossa análise sugere que a atuação da CEPAL nos anos 1950 como Escola do Pensamento foge ao ideário que sustentou a sua criação no final dos anos 1940, assim como é incompatível com a missão

\footnotetext{
${ }^{10}$ Em Almeida Filho (2003), há uma seção em que se exploram as implicações da mudança de estratégia, sobretudo a primazia da estabilização sobre o crescimento, no contexto dos anos 1990. Para nossos propósitos neste artigo, basta a constatação de que há uma mudança importante de perspectiva.

${ }^{11}$ Sobre o Neoliberalismo, ver Anderson (1995), Carcanholo (2004) e Martins (2003).

${ }^{12}$ Uma exposição mais detalhada deste ponto foge aos nossos propósitos neste artigo. $\mathrm{O}$ argumento segue a linha de afirmar a existência de um processo civilizatório nos limites do capitalismo. Neste processo, o espaço supranacional seria de exercício da hegemonia política dos países impérios. Ver, por exemplo, Hobsbawn (1995), Arrighi (1996) e Dos Santos (2000).
} 
específica das comissões econômicas, haja vista a disparidade de atuação da mesma em relação às suas congêneres vinculadas a outras regiões do mundo ${ }^{13}$.

De fato, a CEPAL é uma das cinco comissões econômicas regionais das Nações Unidas (ONU). Segundo os documentos oficiais e informação constante do seu sítio na Internet, ela foi criada para monitorar as políticas direcionadas à promoção do desenvolvimento econômico da América Latina, assessorar as ações encaminhadas para sua promoção e contribuir para reforçar as relações econômicas dos países da área, tanto entre si como com as demais nações do mundo. ${ }^{14}$

Posteriormente, os países do Caribe foram incorporados, ao tempo em que se internalizou a concepção do desenvolvimento social e sustentável, conceito comum aos organismos multilaterais e originalmente adotado pelo Banco Mundial (NOBRE e AMAZONAS, 2002).

Em 1996, os governos-membros atualizaram a missão institucional da CEPAL, estabelecendo que a Comissão se estabelecesse como centro de excelência encarregado de colaborar com seus Estados-membros na análise integral dos processos de desenvolvimento. A missão inclui, ainda, a formulação, o seguimento e a avaliação de políticas públicas, e a prestação de serviços operativos nos campos da informação especializada, assessoramento, capacitação e apoio à cooperação e coordenação regional e internacional.

Todos os países da América Latina e do Caribe são membros da CEPAL, junto com algumas nações desenvolvidas, tanto da América do Norte como da Europa, que mantêm fortes vínculos históricos, econômicos e culturais com a região. No total, os Estados-membros da Comissão são quarenta e quatro (44) e oito (8) membros associados, condição jurídica acordada para alguns territórios não-independentes do Caribe.

Os Estados-membros são: Alemanha, Antígua e Barbuda, Argentina, Bahamas, Barbados, Belize, Bolívia, Brasil, Canadá, Chile, Colômbia, Costa Rica, Cuba, Dominica, Equador, El Salvador, Espanha, Estados Unidos da América, França, Granada, Guatemala, Guiana, Haiti, Honduras, Itália, Jamaica, Japão, México, Nicarágua, Países Baixos, Panamá, Paraguai, Peru, Portugal, Reino Unido da Grã-Bretanha e Irlanda

\footnotetext{
${ }^{13}$ A afirmação é aceitável no que diz respeito à atuação da CEPAL como Escola do Pensamento, condição bem distinta das demais agências: a Comissão Econômica para a África - ECA (com sede em Adis Abeba), a Comissão Econômica e Social para a Ásia e o Pacífico - ESCAP (Bancoc), a Comissão Econômica para a Europa - ECE (Genebra), e a Comissão Econômica para a Ásia Ocidental - ECWA (Beirute). Os elementos que utilizamos para dar base à afirmação são a ausência de referências a contribuições dessas outras agências no debate histórico do desenvolvimento, além das informações constantes dos seus sites oficiais, que fazem um relato histórico das suas ações principais.

${ }^{14} \mathrm{http}$ //www.eclac.org/cgi-bin/getProd.asp?xml=/brasil/noticias/paginas/2/5562/p5562.xml\&xsl=/ brasil/tpl/p18f.xsl\&base=/brasil/tpl/top-bottom.xsl . Acessado em 10 de julho de 2010.
} 
do Norte, República Dominicana, República da Coréia, Santa Lúcia, São Cristóvão e Neves, São Vicente e Granadinas, Suriname, Trinidad e Tobago, Uruguai e Venezuela.

Os Países-membros associados são: Anguilla, Antilhas Holandesas, Aruba, Ilhas Virgens Britânicas, Ilhas Virgens dos Estados Unidos, Montserrat, Porto Rico, Ilhas Turcas e Caicos.

Na sistemática que vem sendo adotada, pelo menos desde os anos 1990, a cada dois anos, a CEPAL convoca representantes técnicos e de nível ministerial procedentes de seus Estados-membros para debater temas substantivos relacionados ao desenvolvimento econômico e social da região, examinar as atividades realizadas pela Comissão no biênio anterior e fixar as prioridades de seu Programa de Trabalho para o biênio seguinte ${ }^{15}$. Essas reuniões conformam o denominado Período de Sessões da CEPAL, que ocorre a cada vez em um país-membro distinto, atuando este como anfitrião. Nesse período, é aprovado o documento síntese, que serve de referência para a posição da instituição e mesmo para a realização de estudos técnicos setoriais. É justamente a esses documentos que fizemos referência na seção anterior para caracterizar uma mudança de perspectiva.

A missão, a estrutura e o funcionamento da CEPAL seguem um modelo regular da ONU, de modo que o seu funcionamento confunde-se com o dos organismos multilaterais em geral, e mesmo com a sistemática de operação dos órgãos centrais das Nações Unidas ${ }^{16}$.

Quanto à parte operacional, a agência dispõe de uma Secretaria formada por uma equipe de funcionários que, junto com alguns consultores, têm a responsabilidade de desenvolver o Programa de Trabalho do Sistema CEPAL, sob a direção de um Secretário Executivo.

Portanto, parece-nos natural que nessas condições de constituição organizacional, forma de operação e conjuntura histórica, em que as deliberações são tomadas pelos Estados-membros, os documentos sejam, sobretudo, de síntese das posições das políticas econômicas regionais, e muito menos uma posição de vanguarda, efetivamente propositiva.

\footnotetext{
${ }^{15}$ A divulgação periódica de documentos é da tradição da CEPAL. O documento tomado como referência de pensamento para a "Escola" é o Estudo Econômico da América Latina de 1949. Ver, a este respeito, Bielschowsky (2000) e Rodrigues (2009).

${ }^{16}$ Em Murphy (1994), há uma discussão detalhada de um possível papel ativo das instituições multilaterais no desenvolvimento capitalista global. Há, ainda, um detalhamento do funcionamento das Nações Unidas e dos seus órgãos, indicando uma forma muito mais articulada do que a que transparece pela divulgação da ação independente de cada um dos órgãos multilaterais.
} 
Uma maneira de reconhecer esse caráter no corpo dos documentos oficiais é verificar o avanço que foi feito na elaboração dos diagnósticos, que são muito mais amplos do que aqueles dos anos 1950, incorporando temas sociais, em comparação a um esforço relativamente pequeno de recomendações de políticas. Estas ficam circunscritas a "lições" da experiência exitosa de países da região e do mundo ${ }^{17}$.

Duas passagens comparativas dos documentos mais marcantes da história da CEPAL (Estudio Económico, 1949; e Transformación Productiva, 1990), e que aqui estamos tomando como emblemáticos de duas fases, servem muito bem para mostrar a diferença de perspectiva de atuação da Agência. Comecemos pelo Estudio:

Em resumo, a discrepância entre os raciocínios teóricos, baseados na mobilidade absoluta dos fatores produtivos, e os fenômenos reais da economia têm um significado tão grande para a teoria do desenvolvimento econômico da América Latina em especial, e de toda a periferia, em geral, que se impõe um sério esforço de revisão teórica, o qual, partindo de premissas mais compatíveis com a realidade, possa ajudar-nos a formular em bases sólidas as linhas essenciais de uma política de desenvolvimento econômico (p. 157).

Em seguida, passemos ao "Transformación Productiva”:

A interação ativa entre os agentes públicos e privados, assim como a reestruturação do setor público, serão um processo cujo conteúdo e alcance não admitem fórmulas preconcebidas. Não apenas ele dependerá do contexto institucional, social, econômico e político em que se der, como deverá também surgir de um pacto amplo entre as diferentes forças representativas. Por conseguinte, este documento oferece apenas alguns princípios gerais para a ação estatal, em apoio à transformação produtiva com equidade. Entre esses princípios, destacam-se a seletividade nas ações do Estado, a autolimitação destas, a simplificação e a descentralização das intervenções estatais, e melhorias na capacidade de previsão de médio prazo através de novas modalidades de planejamento (p. 903).

${ }^{17}$ Esta forma é contrastante com o primeiro estudo realizado pela CEPAL no seu primeiro ano e publicado em 1949, que tem um notável caráter propositivo. É certo que as conjunturas são bastante distintas, porém o que queremos realçar é a mudança de natureza de conteúdo. Estamos frisando reiteradamente que as circunstâncias do começo de operação da CEPAL eram extraordinárias. 
Ficam claros os distintos conteúdos e alcance dos dois documentos. Cabe observar que a Escola Cepalina, à qual o primeiro documento está articulado, é considerada "heterodoxa" na tradição das Teorias do Desenvolvimento ${ }^{18}$, disciplina que nasce nos anos $1950^{19}$, justamente porque se afastava claramente do pensamento hegemônico que dominou as formulações sobre desenvolvimento e subdesenvolvimento no pós-guerra.

Com efeito, a CEPAL contestou abertamente a Lei das Vantagens Comparativas e a inserção internacional das economias latino-americanas que, mantidas as condições do imediato pós-guerra, estariam condenadas a uma situação permanente de atraso. A proposição dominante neste campo apontava para uma ação do Estado que quebrasse as barreiras à disseminação do capitalismo, ainda incipiente nos países da América Latina. Uma vez que o mesmo se estabelecesse, o crescimento da produção ocorreria mais rapidamente nos países da região do que nos países já desenvolvidos, pela operação dos rendimentos crescentes e decrescentes, encurtando o "hiato" entre as condições sociais desses dois grupos.

A proposta da CEPAL para a superação da condição periférica foi, como sabemos, a da industrialização pela ação ativa do Estado. Denotava assim da formulação cepalina que a condição de subdesenvolvimento não era uma condição inalterável, que não pudesse ser modificada pela ação interna das próprias sociedades. Em outras palavras, considerava a CEPAL que não havia um determinismo histórico da condição de subdesenvolvimento.

Em contraste com essa posição mais à esquerda, digamos assim, que ocupava no campo das "Teorias do Desenvolvimento Econômico", a Escola Cepalina é vista no debate latino-americano sobre desenvolvimento como reformista (uma posição de centro), uma vez que a referência é, neste caso, a aceitação resignada do capitalismo. A Escola da Dependência, por exemplo, partiu de uma crítica ao pensamento cepalino para formular as suas idéias, mostrando claramente os limites da mesma ao

\footnotetext{
${ }^{18}$ Em Fonseca (1999: 73-83), há um apontamento sobre a definição de "heterodoxia". A discussão é feita em relação ao pensamento de Getúlio Vargas. Argumenta ele que a heterodoxia se define por uma oposição à ortodoxia, ambas historicamente determinadas e indispensavelmente relacionadas a um determinado paradigma científico ou ideologia. Portanto, em analogia, a heterodoxia da CEPAL estabelece-se em oposição à ortodoxia econômica dos anos 1950 e, mesmo, como está frisado no texto, ao pensamento dominante no campo do desenvolvimento econômico. Para uma forma bastante consistente de separar ortodoxia da heterodoxia no campo da economia, ver Mollo (2004).

${ }^{19}$ A este respeito, ver Hirschman (1981). Há uma interessante discussão a respeito dos resultados históricos das estratégias de desenvolvimento, mostrando o fracasso de todas elas. É evidente que o fracasso está referenciado à permanência da condição de subdesenvolvimento ou de atraso. Ele refere-se ao conjunto das teorias de desenvolvimento como compondo uma subdisciplina da Economia.
} 
desconsiderar qualquer tratamento das classes sociais (CARDOSO, 1995) ${ }^{20}$. Com o mesmo sentido, a formulação da Industrialização Retardatária - Capitalismo Tardio - feita por Mello (1982: cap.2), apresenta-se como uma superação dialética da perspectiva cepalina, apontando algumas insuficiências de análise ${ }^{21}$.

O ponto que queremos aqui levantar é que esta possibilidade, que foi exercitada no passado, de intervir de algum modo no debate teórico do desenvolvimento, não existe mais. Entendemos que são duas as razões principais. A primeira vimos de apontar é a forma atual de operação das agências multilaterais, em especial a CEPAL, que funcionam como órgãos assessores de suporte técnico e que buscam consenso de políticas, no caso, políticas de desenvolvimento.

A segunda razão refere-se às condições históricas de desenvolvimento dos anos 1980 e 1990. Após o esgotamento da "fase de ouro do capitalismo", que se inicia no pós-segunda guerra e alcança meados dos anos 1960, abre-se uma fase de transição a um novo "estilo de desenvolvimento global". Dois aspectos a realçar: a transição se dá com a configuração de um novo padrão tecnológico, que permitiu uma integração sem precedentes dos mercados financeiros nacionais e uma aceleração da integração produtiva, diminuindo progressivamente a importância dos mercados domésticos em relação ao mercado internacional; e há uma fragilização financeira dos Estados nacionais, seja pela perda de importância relativa dos mercados domésticos, seja pelas mudanças que ocorrem nos mercados financeiros.

Sobre essas últimas mudanças, é preciso enfatizar que talvez a mais importante seja relacionada à natureza dos fluxos financeiros, pois parte da transição se dá com quebra de regras de convivência entre os Estados nacionais. Dessas regras, merece atenção a que permite a flutuação livre das taxas de câmbio em condições de forte volatilidade dos movimentos de capitais, pois estas taxas abalaram, em todos os períodos de instabilização das condições de desenvolvimento global, as finanças nacionais ${ }^{22}$.

As proposições teóricas da CEPAL sustentaram as políticas econômicas dos anos 1950 e 1960, embora já nesta última década tenham perdido influência. Esta é uma circunstância comum ao conjunto das teorias do desenvolvimento das quais as

\footnotetext{
${ }^{20}$ Estamos aqui apenas fazendo referência a uma crítica à CEPAL feita por autores de uma "Escola". Há, evidentemente, críticas a serem feitas à formulação de dependência. Para uma discussão específica, ver Araújo e Almeida Filho (2001).

${ }^{21}$ Essas referências de contextualização teórica são importantes para uma avaliação do significado do "Transformación Productiva". Entendemos que a tradição cepalina nunca considerou a possibilidade de ruptura com a ordem capitalista. Isto, de certa forma, determinou uma acomodação das estratégias de desenvolvimento à hegemonia exercida pelo neoliberalismo nos anos 1990.

${ }^{22}$ ver, a este respeito, Belluzzo (1995), Chesnais (1998; 2005), Harvey (2004) e Almeida Filho e Paulani (2009)
} 
proposições da CEPAL são uma parte. As políticas de desenvolvimento que foram decorrentes das abordagens teóricas do desenvolvimento não alcançaram os resultados esperados, sobretudo a diminuição do hiato entre os níveis de desenvolvimento dos países capitalistas.

Por razões que merecem em si uma análise à parte, essas teorias não foram requalificadas, ou adaptadas, às novas condições do desenvolvimento global, particularmente as condições dos anos 1970, com queda da institucionalidade de Bretton Woods e aceleração do processo inflacionário. Por esta razão, abre-se um período de transição (teórica e ideológica) só terminado nos anos 1990.

Para completar nossas observações sobre a natureza da ação da CEPAL desde os anos 1990, vale uma referência a quatro outros elementos que interferiram na moldagem e conteúdo do debate internacional sobre desenvolvimento no mesmo período e da "governança multilateral".

O primeiro é que o tema do desenvolvimento se fragmentou em diversas dimensões, conforme está sustentado em Cardoso (1995), que o caracteriza como o "mais político dos temas". Há um conjunto de razões para isto. Hirschman (1981) sintetiza essas razões dizendo que o tema do desenvolvimento econômico havia deixado de ser o núcleo das estratégias do desenvolvimento dos Estados nacionais, pois as políticas sugeridas a partir do âmbito teórico (teorias do desenvolvimento) não haviam sido capazes de solucionar os problemas sociais básicos, menos ainda as disparidades de níveis de desenvolvimento econômico. Além disso, o "desenvolvimento econômico" não alcançava aspectos fundamentais ao contexto dos anos 1970, sobretudo o tema ambiental, relacionado não apenas ao esgotamento das fontes de recursos naturais, como também à deterioração provocada pela forma de produção, voltada para o consumo de massa.

Em decorrência disso, vem um segundo elemento, que está relacionado à emergência do tema do desenvolvimento sustentável como o novo foco das ações das agências multilaterais nos anos 1980 e 1990. Em Nobre e Amazonas (2002), há uma discussão a respeito da evolução histórica do conceito e das suas definições que mostra bem as circunstâncias que fizeram deste novo conceito uma referência em questões do desenvolvimento.

... o debate em torno do sentido do conceito de DS [desenvolvimento sustentável] é amarrado, em última instância, por diferentes visões de como deva se dar a institucionalização da problemática ambiental. Em outras palavras, não obstante as diferentes visões, a noção de DS é o carro-chefe de uma estratégia de institucionalização da problemática ambiental. Uma tal estratégia comporta pelo menos dois objetivos principais a serem alcançados: tanto elevar o meio ambiente à condição de issue de primeira grandeza na agenda política internacional, como fazer com que o problema ambiental passe a 
permear a formulação e a implementação de políticas públicas em todos os níveis nos Estados nacionais e nos órgãos multilaterais e de caráter supranacional. Esta perspectiva nos permite, de um lado, interpretar todos os conceitos globais anteriores (como, por exemplo, o ecodesenvolvimento e a estratégia de conservação mundial) como tentativas incompletas e imperfeitas de alcançar esse objetivo de institucionalização, ao mesmo tempo em que o DS significa justamente a consumação dessa institucionalização. De outro lado, essa perspectiva nos permitiu estabelecer alguns marcos nesse processo de institucionalização, caso em que, por exemplo, a Rio-92 passa a ser o ponto de inflexão, por excelência, do processo. (NOBRE e AMAZONAS, 2002, p. 8)

Como dissemos, a consolidação desse debate ocorreu no âmbito supranacional, tendo colocado em confronto direto a perspectiva dos países desenvolvidos e dos periféricos, que passou a ser referida como confronto de interesses entre o Norte e o Sul23.

Um terceiro elemento está desenvolvido em Murphy (1994) que toma o espaço supranacional como âmbito do que chama de "governança global". Para ele, a governança é uma forma de regulação, que vai se constituindo pari passu ao desenvolvimento do capitalismo avançado, apresentando fases aproximadas ao que a historiografia econômica chama de "revoluções industriais". Assim, uma das transições entre fases ocorrerá justamente nos anos 1970, coincidindo com o período em que o tema do desenvolvimento deixa de ser o centro das ações de desenvolvimento nacionais e internacionais.

O sentido da "governança global" é de uma institucionalidade de suporte ao processo de desenvolvimento capitalista, portanto o de uma ação integrada em favor da acumulação global. A "institucionalidade" teria assim força suficiente para intervir na dinâmica de cada um dos órgãos multilaterais que compõem o esquema da ONU.

Este é um ponto importante para nossa tese de que a CEPAL de hoje opera nos termos tradicionais de uma organização multilateral, pois a institucionalidade que nos aponta Murphy inclui regras de operação que são incompatíveis com a condição de uma Escola de Pensamento. Nesse caso, a primazia é a convergência de ações que possam estimular o processo de acumulação em escala global, ao contrário do voluntarismo típico de uma Escola, que assume a vanguarda ou a defesa de princípios teóricos ou ações políticas.

Finalmente, todos esses elementos são incorporados e traduzidos por Rodrigues (2009) mediante a formulação do que considera como o neoestruturalismo cepalino.

\footnotetext{
${ }^{23}$ Aqui vale a referência a Kennedy (2006), em que há um capítulo específico para discutir as relações Norte-Sul.
} 
Como se destacou anteriormente, a designação de "estruturalista" com que se caracteriza a teoria do subdesenvolvimento elaborada na CEPAL ao longo dos anos 1950 responde a um tipo de contágio. Com efeito, tal designação provém da que primeiro se usou para identificar a interpretação de diversos processos inflacionários acontecidos na América Latina, que foi tomando corpo, naqueles anos, em artigos de economistas vinculados direta ou indiretamente a essa entidade. Cabe reiterar, entretanto, que o enfoque estruturalista da inflação se elaborou em documentos não-oficiais da entidade mencionada e com certo questionamento de sua direção, particularmente com o de Prebisch.

Algo similar acontece em fins da década de 1980. Aqueles que procuraram interpretar a aceleração dos processos inflacionários ocorridos então na Argentina e Brasil se autodefiniram como "neo-estruturalistas", aludindo a seus vínculos com o pensamento gestado na área, assim como à necessidade de adequá-lo para proceder à interpretação aludida. Assim, uma vez mais - e em curiosa coincidência - um enfoque alternativo relativo à inflação transfere seu nome às teorias e propostas estratégicas sobre o desenvolvimento a longo prazo plasmadas em documentos da CEPAL no início dos anos 1990, que desde então se configuram como eixo central das posições desta instituição. Certas ideias-chave elaboradas por Fernando Faynzylber durante a década de 1980 exercem uma influência muito significativa na conformação e posterior desenvolvimento desta visão neo-estruturalista relativa ao longo prazo (p. 511).

Portanto, sustenta Rodrigues que parte daquilo que se convencionou chamar de interpretação da CEPAL nos anos 1950 foi fruto de esforços independentes, situação que se repetiria nos anos 1990, agora já no contexto de hegemonia do Neoliberalismo. Contudo, a citação aqui foi feita para atestar que mesmo um autor como Octávio Rodrigues, que foi parte dos esforços originários de desenho de uma interpretação alternativa - tanto para as condições históricas do desenvolvimento dos anos 1950, quanto para as proposições que se seguiram de industrialização pela via da ação direta e indireta do Estado - reconhece que a nova interpretação está em muito influenciada pelas ideias-chave de Fernando Faynzylber.

\section{CONCLUSÕES}

Considerando os propósitos deste artigo, podemos apresentar as conclusões como um conjunto de quatro pontos-síntese de nossas proposições:

i) há inequivocamente um novo conjunto de ideias e proposições que sustentam a ação estratégica da CEPAL desde os anos 1990. Isto é reconhecido tanto pelos críticos à Agência quanto por importantes colaboradores como Octávio Rodrigues e Ricardo Bielshowsky;

ii) nossa tese é que essas ideias são funcionais, ou mais próximas, das proposições que norteiam as ações de outros organismos multilaterais que têm missões institucionais relacionadas ao desenvolvimento, como são o FMI, o 
Banco Mundial, a OMC e, mesmo, as outras quatro comissões econômicas regionais. Atribuímos esta aproximação ao progresso de uma governança das Nações Unidas, que ainda era incipiente nos anos 1950;

iii) entendemos que essa tese não é contraditória ao reconhecimento de que a CEPAL mantenha vínculos históricos com os temas que foram base da seu reconhecimento como Escola do Pensamento nos anos 1950 e 1960, nos termos considerados por Bielshowsky (2000);

iv) concluímos que a CEPAL ainda realiza pesquisas e diagnósticos relevantes para a região da América Latina, porém que não tem mais condições de realizar um papel de Escola de Pensamento, pois, para isso, seria imprescindível uma independência de atuação que os organismos multilaterais não têm, pelo menos desde os anos 1990.

\section{REFERÊNCIAS}

ALMEIDA FILHO, N. "O Desenvolvimento da América Latina na Perspectiva da CEPAL nos Anos 1990: correção de rumos ou mudança de concepção?” In: FERRAZ, J. C.; CROCCO, M.; ELIAS, L. A. (org.). Liberalização econômica e desenvolvimento. São Paulo: Editora Futura, 2003, p. 100-123.

ALMEIDA FILHO, N. e PAULANI, N. "Regulação Social e Acumulação por Espoliação reflexão sobre as teses da financeirização e a caracterização do capitalismo contemporâneo". Anais do XIV Encontro Nacional de Economia Política. São Paulo: PUCSP, 2009.

ANDERSON, P. “Balanço do Neoliberalismo”. In: GENTILI, P. (org.). Pós-neoliberalismo: As políticas sociais e o estado democrático. Rio de Janeiro: Paz e Terra, 1995, p. 9-23.

ARAÚJO, E. S. e ALMEIDA FILHO, N. "Notas para uma Teoria do Desenvolvimento Capitalista na Periferia: Contribuições e Limites da Teoria da Dependência”. In: Anais do VI Encontro Nacional da SEP. São Paulo: jun. de 2001.

ARRIGHI, G. O longo século XX - dinheiro, poder e as origens de nosso tempo. São Paulo: Contraponto/UNESP, 1996.

BELLUZZO, L. G. M. "O declínio de Bretton Woods e a emergência dos mercados "globalizados”. Economia e Sociedade (4). Campinas: IE/UNICAMP, junho de 1995.

BIELSCHOWSKY, R. (org.). Cinquenta anos de pensamento da CEPAL. Rio de Janeiro: Editora Record, 2000.BIELSCHOWSKY, R. "Cinquenta Anos de Pensamento na CEPAL - uma resenha”. In BIELSCHOWSKY, R. (org.) op. cit.

CARCANHOLO, M. D. "Neoliberalismo e Desenvolvimento em uma Economia Periférica". In: CHAVIER, C. L. (org.). Desenvolvimento Desigual. Uberlândia: Edufu, 2004.

CARDOSO DE MELlO, J.M. O Capitalismo Tardio. São Paulo: Brasiliense, 1982. 
CARDOSO, F.H. "Desenvolvimento: o mais político dos temas econômicos". Revista de Economia Política (15) 4. São Paulo: Nobel, out.-dez. de 1995.

CEPAL. "Estudo Econômico da América Latina”, 1949 In: BIELSHOWSKY, R. (org.). Cinquenta Anos de Pensamento da CEPAL. v. 1. Rio de Janeiro: Editora Record, 2000, p. 137-178. . Transformación Productiva com Equidad. Santiago: 1990. . Panorama de la inserción internacional de América Latina y el Caribe. Santiago: 1996. Equidad, Desarollo y Ciudadania. Santiago: 2000.CEPAL (Ed.). "Desarrollo productivo en economías abiertas". Síntesis. Santiago: 2004.

CEPAL (Ed.). La transformación productiva 20 años después. Viejos problemas, nuevas oportunidades. (coordinación José Luis Machinea, con la colaboración de Juan Martín y Mario Cimoli). Santiago: 2008.

CHESNAIS, F. “Mundialização Financeira e Vulnerabilidade Sistêmica”. In: Chesnais, F. (org.). A Mundialização Finaceira. São Paulo: Xamã, 1998.

.'O Capital Portador de Juros: acumulação, internacionalização, efeitos econômicos e políticos”. In: Chesnais, F. (org.). Finança Mundializada. São Paulo. Boitempo, 2005.

CORAZZA, G. O “regionalismo aberto" da Cepal e a inserção da América Latina na Globalização. Porto Alegre: Ensaios FEE, v. 27, n. 1, p. 135-151, 2006.

CORREA, H. F. de S. e CARCANHOLO, M. D. A Nova CEPAL e o "Mal-estar" Social na América Latina, 2007. Disponível em http://www.sep.org.br/artigo/2_congresso/_737_1 00c5903a359249950e80eec31105ab6.pdf . Acesso em 08/06/2011.

DOS SANTOS, T. A Teoria da Dependência - Balanço e Perspectivas. Rio de Janeiro: Civilização Brasileira, 2000.

FAJNZYLBER, F. La industrialización trunca de América Latina. Distrito Federal do México: Editorial Nueva Imagen, 1983.

"Industrialización en América Latina: de la "caja negra" al "casillero vacío": Comparación de patrones contemporáneos de industrialización". Cuadernos de la CEPAL, Santiago: Núm. 60, Nações Unidas, 1989.

FONSECA, P. C. D. Vargas: o capitalismo em construção. São Paulo: Brasiliense, 1999 [1989].

HARVEY, D. O Novo Imperialismo. São Paulo, Edições Loyola, 2004.

HIRSCHMAN, A.O. “The Rise and Decline of Development Economics”, 1981. Reprinted in Kanth, R. Paradigms in Economic Development. London, England: Sharpe, 1994, p. 191-210.

HOBSBAWM, E. Era dos extremos; o breve século XX: 1914-1991. São Paulo, Companhia das Letras, 1995. 
HETTE, B. Development Theory and the Three Worlds. SAREL Report, R-2, Estocolmo: 1990.

HUNT, D. Economic Theories of Development. London: Harvester, 1989.

"Análise da Dependência no início do século XXI: algumas questões importantes" (mimeo). Texto apresentado no II Workshop Internacional Economia \& Desenvolvimento, IE-UFU, 2003.

KAY, C. Latin American Theories of Development and Underdevelopment. Londres: Routledge, 1989.

KENNEDY, P. The parliament of man - the past, present, and future of the United Nations. New York: Random House, 2006.

MARTINS, C.E. Globalização, dependência e neoliberalismo na América Latina. Tese de doutorado. Departamento de Sociologia da USP, em maio de 2003.

MURPHY, C.N. International Organization and Industrial Change - global governance since 1850. New York: Oxford University Press, 1994.

NOBRE, M. e AMAZONAS, M.C. Desenvolvimento Sustentável: a instituicionalização de um conceito. Brasília: edições IBAMA, 2002.

RODRIGUES, O. O estruturalismo latino-americano. Rio de Janeiro: Civilização BrasileiraCEPAL, 2009.

VITAGLIANO, L. F. "Neo-estruturalismo: a CEPAL revisita o desenvolvimento e encontra a desigualdade." Paper presented at the annual meeting of the ISA - ABRI JOINT INTERNATIONAL MEETING, Pontifical Catholic University, Rio de Janeiro Campus (PUC-Rio), Rio de Janeiro, Brazil, 22 jul., 2009, http://www.allacademic.com/meta/ p381329_index.html.

WILLIAMSON, J.“The Washington Consensus Revisited”. In EMMERIJ, L. (editor). Economic and Social Development into XXI Century. Washington: Inter-American Development Bank, 1997, p. 48-61. 